TRABAJOS DE PREHISTORIA

46, 1989, pp. 99-116

\title{
EL TUMULO PROTOHISTORICO DEL «PASO DE LA LOBA». (HUIDOBRO, BURGOS)
}

\author{
POR \\ MANUEL A. ROJO GUERRA (*)
}

RESUMEN En el Noroeste de la provincia de Burgos - comarca de la Lora-, coincidiendo con el área de dispersión del foco dolménico más importante del Oriente de La Meseta Superior, se documentan una serie de enterramientos tumulares pertenecientes a los primeros momentos de la Edad del Bronce. Sirven como alternativas a las deposiciones de la época en los monumentos megaliticos, a los que llegarán a suplantar definitivamente.

El túmulo del «Paso de la Loba" posee, a su vez, elementos más modernos que nos hablan del arraigo de esta peculiar forma de enterramiento en las poblaciones locales y su perduración hasta momentos avanzados de la Edad del Hierro.

\begin{abstract}
In the La Lora district of northwest Burgos province, coinciding with the greatest concentration of dolmens in the eastern part of the Upper Meseta, there is a series of burial mounds which belong to the beginning of the Bronze Age. These served first as alternatives to, and then as replacements for, the megalithic burial places. The barrow of Paso de la Loba has, in turn, more modern elements which indicate that this special burial rite became rooted among the local population and lasted until the later Iron Age.
\end{abstract}

Palabras clave Prehistoria. Edad del Bronce. Enterramiento. Túmulo. Península Ibérica. Meseta Superior. Burgos.

\section{LOCALIZACION Y ENTORNO}

El Túmulo del "Paso de la Loba" recibe este nombre por localizarse en las cercanías de un recinto construido en forma de embudo y destinado a la caza de este animal a donde se le arrinconaba mediante grandes batidas de los pobladores de la comarca. Ubicado en el término municipal de Huidobro, que actualmente depende del ayuntamiento de Los Altos Dobro, sus coordenadas de localización exacta según la hoja $\mathrm{n}^{2} 135$ del M. T. N. escala 1:50.000 coinciden con los $42^{\circ} 41^{\prime} 06^{\prime \prime}$ lat. N. y los $0^{\circ} 06^{\prime} 22^{\prime \prime}$ long. E. respecto del meridiano de Madrid.

Orográficamente se asienta en el fondo de un amplio valle alto, de 1.080 metros sobre el nivel del mar, y sobre unas tierras de arcilla rojiza que en su día soportarían un cultivo cerealístico y

() Dpto. de Prehistoria. Colegio Universitario de Soria. 
leguminoso, pero que en la actualidad están abandonadas a la colonización de arbustos y herbáceas, manteniendo una ocasional cabaña de vacuno.

El paraje, en sentido amplio, alberga un importante conjunto de estaciones arqueológicas diseminadas por toda la ladera norte de la amplia depresión en que se asienta el túmulo de La Loba. Entre ellas cabe citar, al occidente de la misma, el dolmen de Fuenteblanquilla excavado por nosotros y, al oriente, la cista de La Nava Alta ya en término de Villaescusa del Butrón, también excavado recientemente. Pero, a estas dos construcciones megaliticas mencionadas, hay que añadir, muy próximo a La Loba, un campo de túmulos de pequeño porte, de tendencia circular, formados por piedras calizas de mediano tamaño dispuestas, en muchas ocasiones, dibujando círculos concéntricos. Dentro de este campo tumular podria incluirse, como un componente más, el ejemplar que ahora nos ocupa (Fig. 1).

\section{EXCAVACION: PLANTEAMIENTO Y DESARROLLO}

El pequeño porte del túmulo (Fig. 2 y Lám. I.1) no era obstáculo para que destacara, de manera notable, sobre la superficie de las tierras circundantes. El mayor desnivel entre su punto culminante y la periferia frisaba los 1,50 metros, pero era un desnivel engañoso ya que estaba colocado en una ligera pendiente. El aspecto que presentaba, previo a la excavación, era el de un ámplio amontonamiento artificial de piedras que formaban una estructura paracircular de escaso tamaño. En el centro podía advertirse una ligera concavidad no muy profunda, aunque sí bastante dilatada e irregular que contenía un bloque de piedra hincado, desplazado hacia el sector meridional. Estas anomalias resultaron ser producto de remociones y reutilizaciones del monumento. El diámetro máximo del túmulo era de 13 metros, por lo que creímos conveniente - a la hora de plantear la excavación- inscribir el mismo en un gran cuadrado de 13,5 metros $\times 13,5$ metros y subdividirlo posteriormente en unidades de $3 \times 3$ metros dejando entre cada una 0,50 metros de testigo. A estas cuadrículas se las numeró con letras de Este a Oeste (A-B-C-D) y con números de Norte a Sur (1-23-4). Por lo tanto nos encontramos con 16 unidades de $3 \times 3$ metros que engloban totalmente la estructura tumular (Lám. I.2).

Con objeto de hacer más práctico el proceso de excavación iniciamos la misma en los cuadros centrales; ésto es, en B-2, C-2, B-3 y C-3. Se siguió un sistema de excavación en horizontal por niveles, levantando capas sucesivas de escasos centímetros. Del mismo modo, para la toma de datos, se estableció un sistema de ejes cartesianos que coincidian con los bordes de cuadrícula, al tiempo que se fijó un punto 0 en el lugar más prominente del túmulo para medir profundidades. Con estos planteamientos se inició la excavación en los cuadros antes mencionados, teniéndose que ampliar la misma en una nueva unidad (C-4) para poder descubrir totalmente un hoyo que se esbozaba en el cuadro C-3.

\section{RESULTADOS DE LA EXCAVACION}

Los resultados del proceso de excavación de La Loba vamos a analizarlos desde una triple perspectiva: la propia estructura constructiva, los restos arqueológicos exhumados y la adscripción cultural del conjunto. 


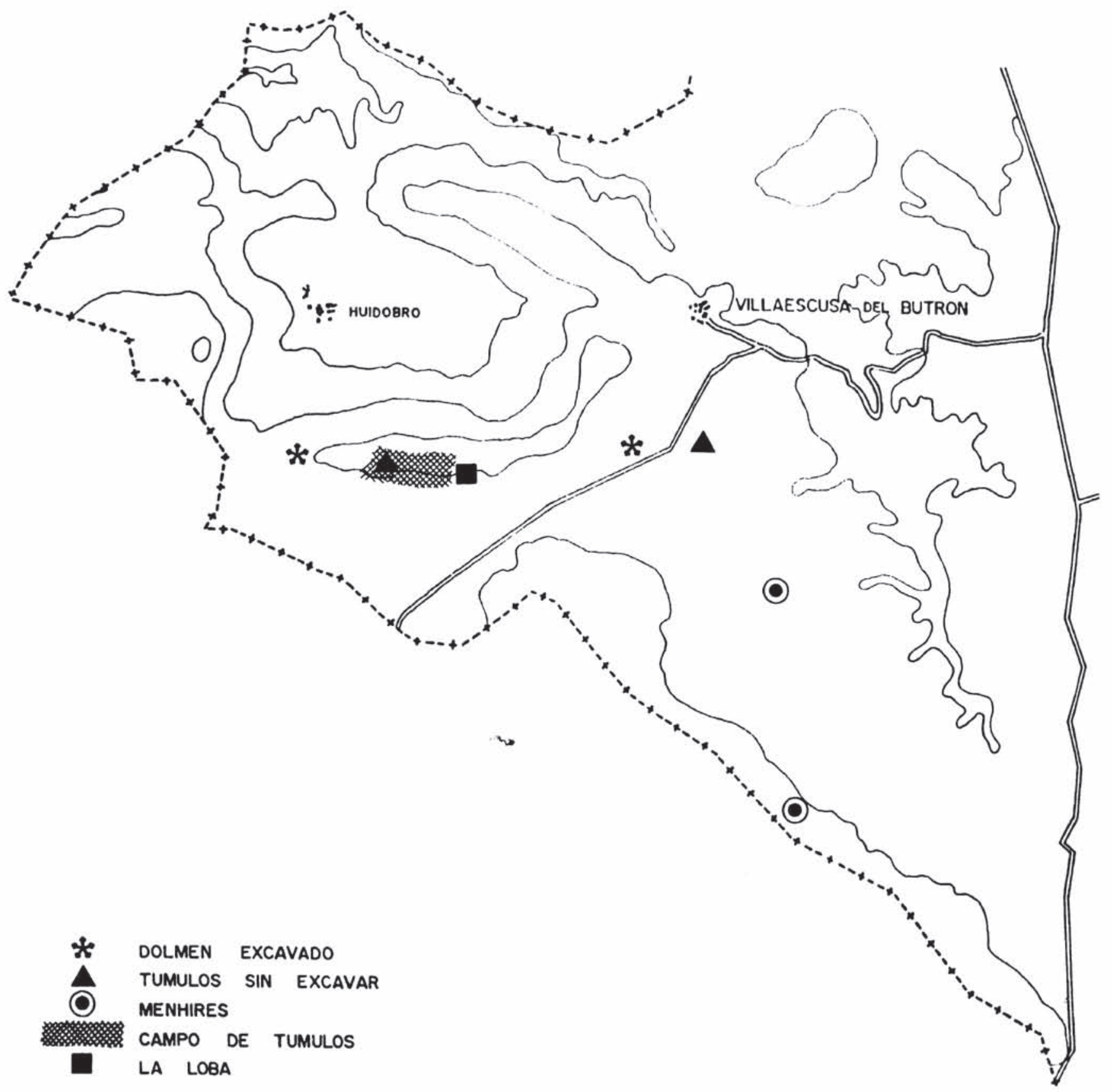

FIG. 1.- Ubicación del túmulo de "La Loba» y estructuras arqueológicas próximas. 

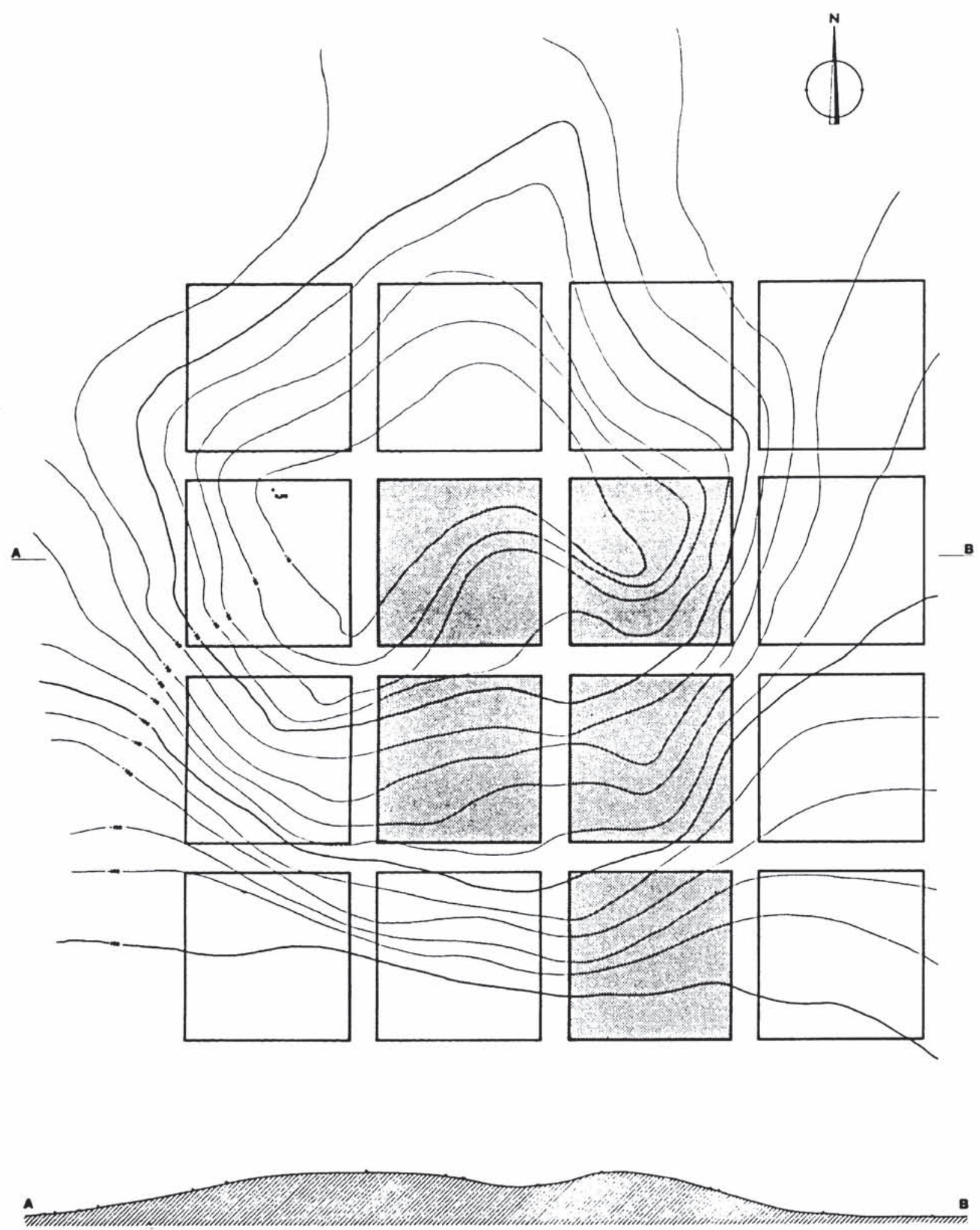

Fig. 2.- Topografía y sección del túmulo de «El Paso de la Lobas. En rayado, la superficie excavada. 
a) Estructura constructiva (Fig. 3 y Lám. II).

Para la erección del monumento se buscó, de forma intencionada, un ligero promontorio dentro de la superficie del páramo. De esta manera, invirtiendo un menor tiempo y esfuerzo se conseguía destacar mejor la estructura. Posteriormente se debió realizar un cráter u hoyo, que albergaría los enterramientos. Sobre esta base se produjo un amontonamiento bastante anárquico de piedras calizas de pequeño y mediano tamaño que configuraron el aspecto general del monumento a modo de "Cairn". Posiblemente, como epílogo a todo el conjunto, se colocó una gran laja de piedra enhiesta sobre el cráter señalando la ubicación de los difuntos.

Las secciones recogidas en la figura 3 reflejan fielmente estas precisiones. Unicamente conviene incidir sobre dos peculiaridades: la existencia de una capa de arcilla limpia no muy potente en el fondo del monumento, inmediatamente por encima de la coraza calcárea del páramo; y la diferente textura que presentan los estratos en las capas de relleno del cráter y de la depresión del centro del túmulo. En el primero de los casos, se trata de un horizonte poco homogéneo y que, a nuestro entender, se ha formado por la descomposición del suelo con la acción de las raíces. En el segundo, los estratos se inclinan en demasía hacia el centro, dibujando falsas cubetas, formados por arcillas de tonalidad más oscura, más suelta y con una proporción notablemente inferior de piedras de tamaño grande. Creemos que esta circunstancia se debe a remociones modernas y violaciones del monumento. Esta impresión viene corroborada por la circunstancia de que los restos óseos y los escasos materiales recuperados - a excepción de la olla cerámica- se encontraban depositados en este área, preferentemente en los testigos B-2/C-2 y C-2/C-3, a la vez que el hoyo que aparece en el testigo C-3/C-4 estaba completamente vacio de cualquier tipo de evidencia arqueológica.

\section{b) Restos arqueológicos}

Los materiales hallados son ciertamente escasos. Sobre el nivel inferior de arcilla rojiza del cuadro B-2 - por tanto en su posición original- hallamos, muy fragmentada pero completa, una gran olla de cerámica (Fig. 4) que presentaba una muy deficiente elaboración a base de arcilla granulosa y escasa cocción por lo que se rompia con suma facilidad y resultaba muy costosa su reconstrucción. No obstante describe una forma muy típica con el cuello inclinado hacia afuera y labio aplanado sobre el que se aplican digitaciones. La panza es saliente, y sobrepasa notablemente el diámetro de la boca con las paredes inclinadas hasta el fondo plano y grueso. La elaboración de la superficie no es homogénea y presenta el cuello alisado que contrasta claramente con la panza y el resto de la olla de superficie muy rugosa. Tiene la decoración ya mencionada sobre el labio y una línea de ungulaciones perpendiculares al borde dispuestas como un anillo alrededor del cuello de la pieza. Sus dimensiones son: $27 \mathrm{~cm}$. de altura por 24,8 de anchura máxima. Diámetro de la boca $18,5 \mathrm{~cm}$.

En posición secundaria hallamos tres objetos más, todos ellos en el nivel superior de revuelto del cuadro C-2 (Fig. 5). Un brazal de arquero sobre arenisca de grano fino, rectangular con dos orificios bicónicos en los extremos. Mide 8,6 cm. de largo por 1,5 cm. de ancho; el botón terminal de una fíbula de pie alzado en bronce que tiene forma circular y posee decoración a base de una circunferencia inscrita de puntitos impresos que rodean un motivo de muelle, en el centro una incisión corrida gruesa enmarca un hoyo más profundo a punzón; por último una pequeña lámina de silex blanquecina de sección tropezoidal con dos aristas longitudinales convergentes en la cara dorsal y la cara ventral lisa y cóncava. Presenta los filos naturales cortantes y el talón facetado. 


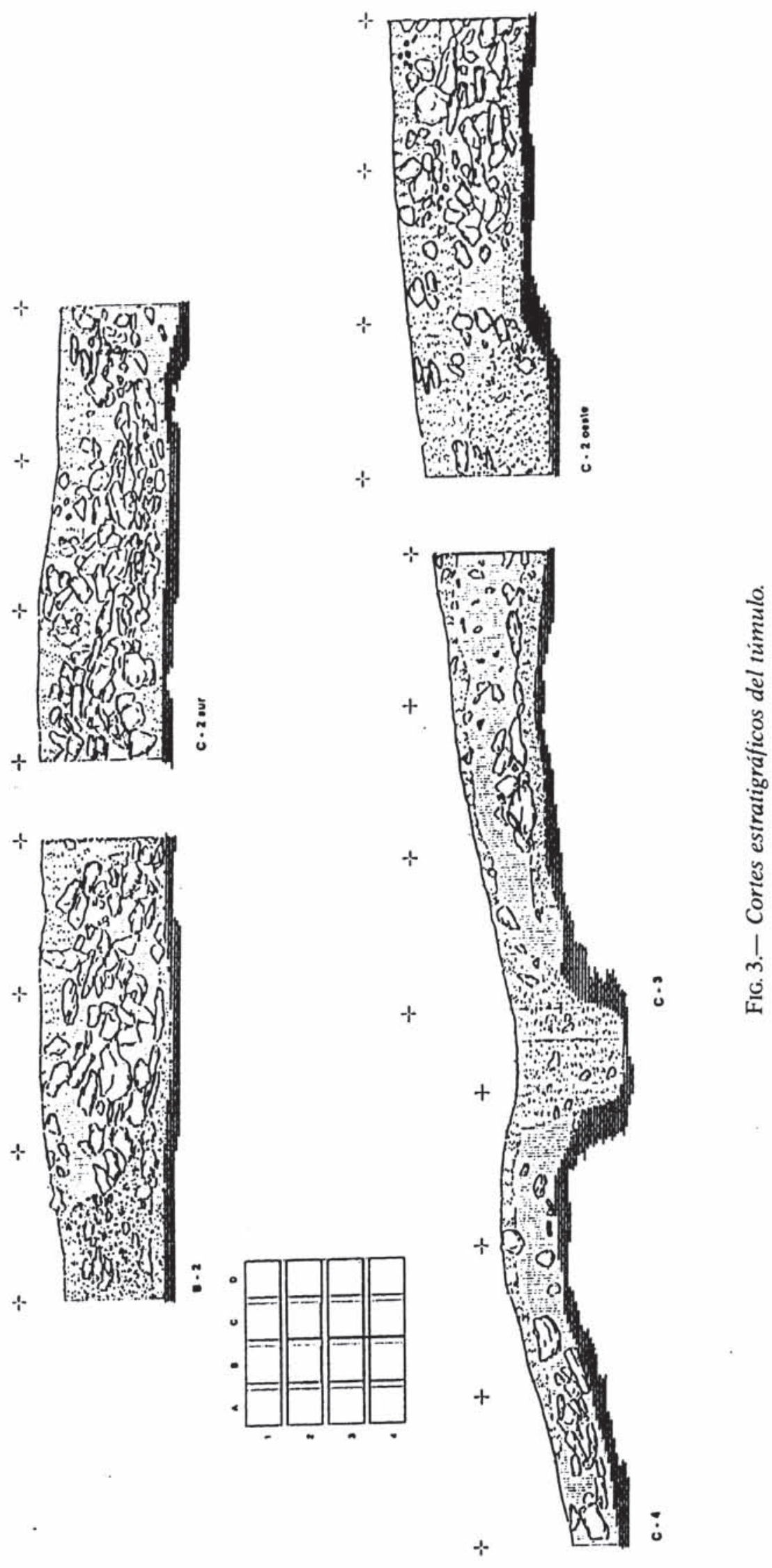



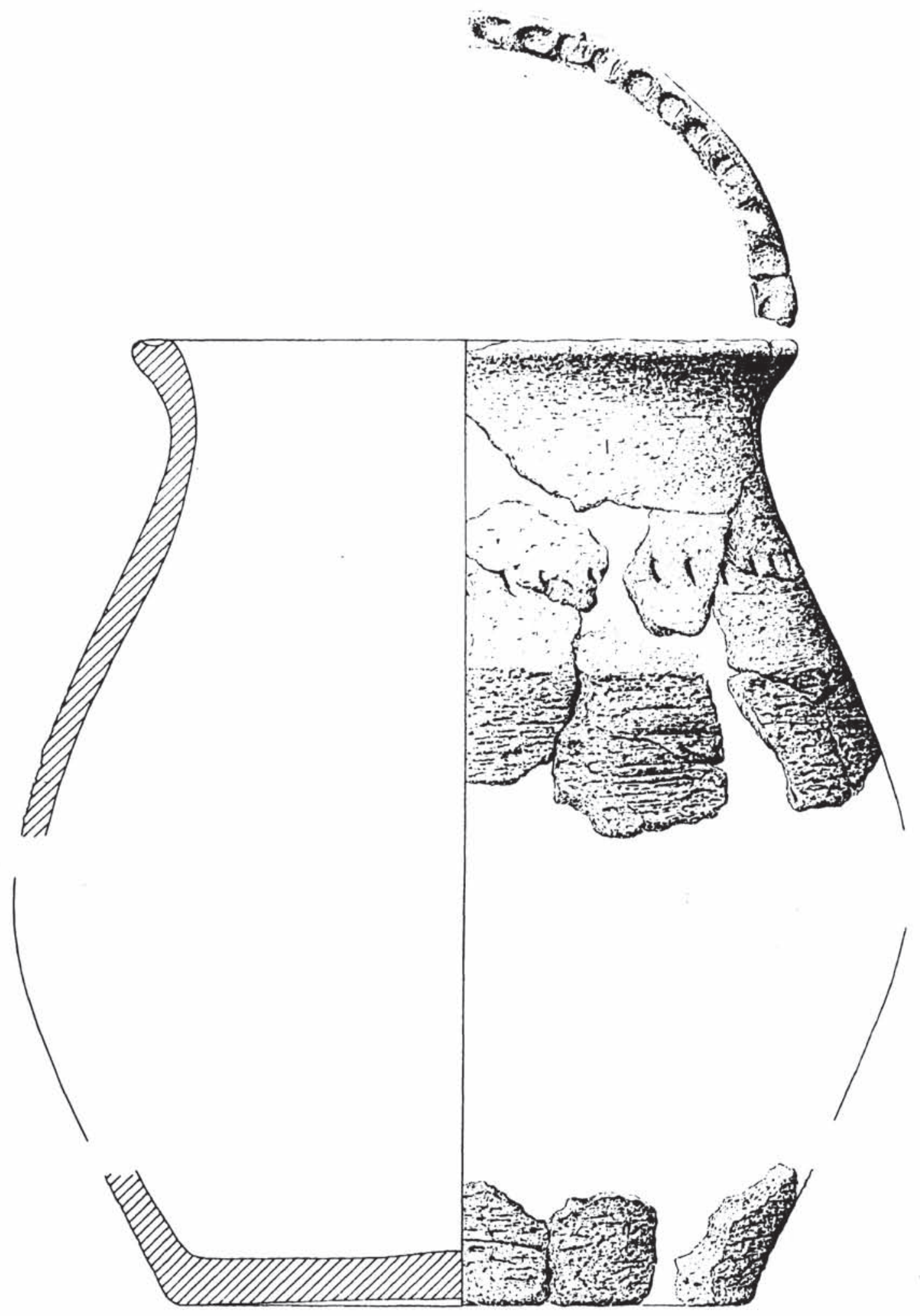

Fig. 4.- Gran olla de cerámica rescatada del nivel inferior del túmulo (Cuadro B-2). 

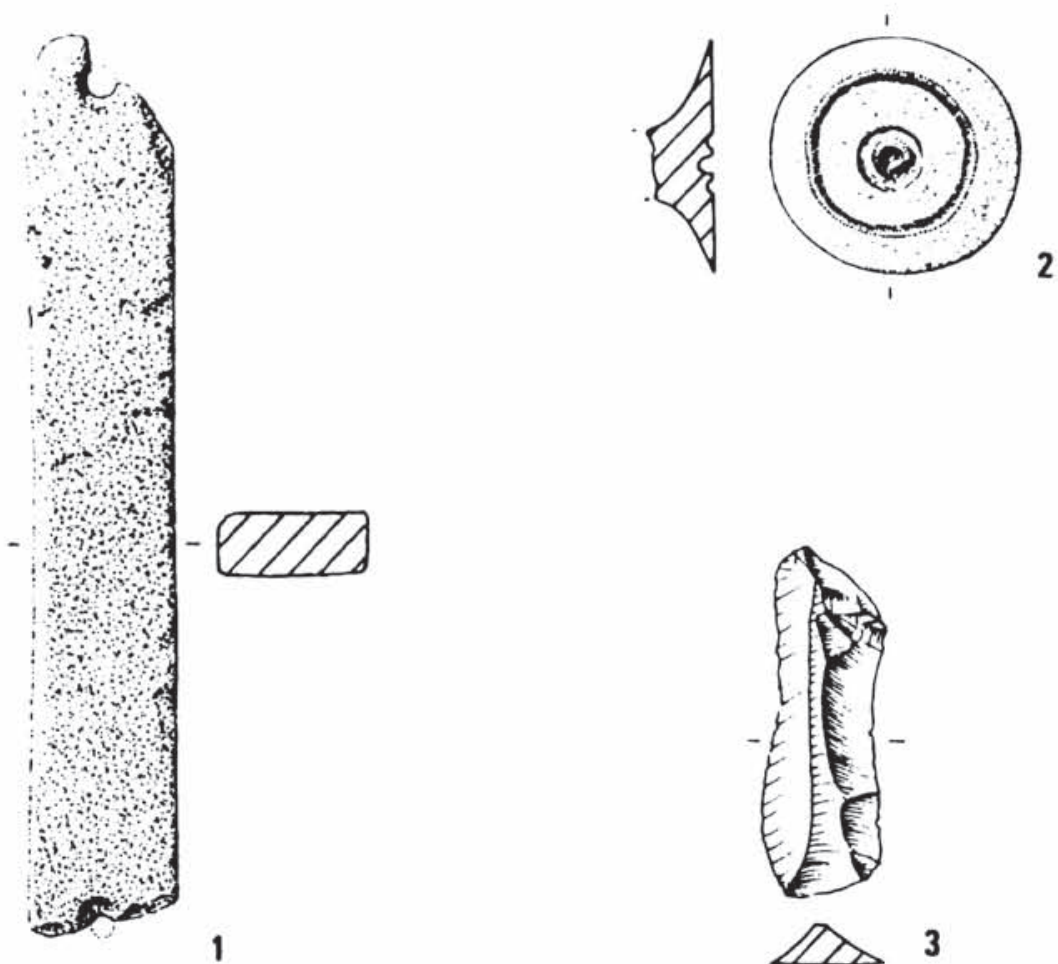

FIG. 5.- Elementos arqueológicos recuperados en la excavación: 1 , brazal de arquero. 2, Botón terminal de una fibula de pie alzado. 3 , lámina de silex blanquecina.

\section{RESTOS OSEOS}

Los restos óseos humanos del túmulo de La Loba han sido estudiados por el Prof. Francisco Etxeberría Gabilondo miembro del Departamento de Medicina Legal de la Universidad del País Vasco y del Departamento de Antropología s. c. Aranzadi de San Sebastian. Asimismo las apreciaciones sobre los escasos restos de animales se deben al Prof. Jesús Altuna. A continuación reflejamos en su totalidad el contenido de dichos estudios.

\section{a) Descripción del material}

Se trata de un material muy fragmentado que alcanza un peso total de $3.000 \mathrm{gr}$. De coloración homogénea pardo clara y textura frágil, muestra signos de corrosión por efecto de la acidez propia de raíces vegetales que, en algún caso, se localizan en los intersticios de los huesos. A excepción de 69 gr. que pertenecen a fauna, el resto corresponden al genero «homo».

\section{Inventario}

- 47 fragmentos de cráneo (mismo individuo).

- 9 vertebras dorsales.

-4 vértebras lumbares.

- 25 fragmentos de vértebras.

-41 fragmentos costales. 
- Región articular de escápula (izda. y drcha. mismo individuo).

- Región articular de escápula (izda. y drcha. mismo individuo).

- Clavicula izquierda.

- Dos fragmentos de diáfisis de clavículas.

- Dos fragmentos de diáfisis de húmeros (dcho. e izdo. mismo individuo).

- Fragmento de cabeza de húmero.

- Esquirla de cabeza de húmero.

- 2 fragmentos proximales de cúbito (drcho. e izdo. mismo individuo).

- 6 fragmentos de diáfisis cúbito y 1 fragmento epifisis distal del mismo.

- 3 fragmentos de coxal (mismo individuo)

- Esquirla de coxal.

- Fragmento de cóndilo de fémur.

- Tercio distal de fémur.

- 2 fragmentos de diáfisis de fémur.

- 5 fragmentos de diáfisis de radio.

- Extremo distal de radio.

- 9 fragmentos de diáfisis de tibias.

- 5 fragmentos de peroné.

- Rótula izquierda.

- Astrágalo y calcáneo izquierdos (mismo individuo).

- Astrágalo y calcáneo derechos (mismo individuo).

- Astrágalo derecho.

- 10 metacarpianos.

- 11 metatarsianos.

- 3 fragmentos metatarsianos.

- 2 huesos del carpo.

- 1 hueso del tarso.

- 3 falanges proximales $1^{\circ}$ dedo de pie.

- 15 falanges (manos y pies).

- 35 esquirlas diáfisis de huesos largos.

- 496 gr. de esquirlas.

- Restos de fauna: pertenecientes a cabra, vaca y aves.

- Maxilares: MAXILAR SUPERIOR

MAXILAR INFERIOR

$\begin{array}{llcll}\text { piezas conservadas } & --65-3--, & 12345678 & \\ \text { Usura (*) } & \text { II } & \text { II } & \text { I } & \text { I } \\ \text { piezas conservadas } & 87654321, & 12345678 & \\ \text { Usura } & \text { II II } & \text { II } & \text { I } & \text { I } \\ \text { piezas conservadas } & 876 & -678 & \\ \text { Usura } & \text { 00I } & \text { I00 } & \end{array}$

MAXILAR INFERIOR

- Se conservan además 10 piezas dentarias sueltas (tres de ellas con máximo grado de desgaste dentario).

(*) Según la clasificación de BRABANT.

\section{Determinación de individuos sexo y edad}

El conjunto de restos representan a tres individuos de modo muy desigual. Mientras que de uno se conservan piezas de todo su esqueleto más o menos completo, otro apenas es reconocido por algún hueso compacto y el tercero tan solo por piezas dentarias sueltas.

El sexo se determina con claridad en el individuo mejor representado y corresponde a un varón de edad adulta joven. El segundo individuo también parece un varón de edad adulta joven y mayor que el anterior. El tercero resulta arriesgado de sexar y es el de mayor edad. De todos modos, los tres son adultos jóvenes. 


\section{Patologia} lógicos.

Se detectan dos estigmas de distinta nosologia y de relativa frecuencia en los estudios paleopato-

Observación 1: se trata de dos porciones de arco vertebral pertenecientes a la $6 .^{\mathrm{a}}$ y $7 .^{\mathrm{a}}$ vértebras cervicales en su hemilado derecho, los cuales se encuentran fusionados en bloque. Desde la articulación de las facetas posteriores en el lado derecho y a lo largo de las láminas de ese lado, se establece un sólido puente de unión que fusionaria ambas vértebras. No existen evidencias de las articulaciones facetarias posteriores, y la ausencia de exótosis a ese nivel permite suponer que se trata de una sinóstosis congénita.

Observación 2: Cuerpo vertebral perteneciente a $4 .^{\mathrm{a}}$ vértebra lumbar que presenta osteofitos discretos en reborde anterior y superior. Estimamos se trata de los habituales procesos degenerativos que afectan a la columna vertebral (artropatia degenerativa).

\section{c) Adscripción cultural del conjunto}

El hecho de que dispongamos de tan escasas evidencias arqueológicas nos obliga a considerar distintos factores en conjunto para poder aproximarnos lo más científicamente posible al contexto cultural y cronológico del túmulo de La Loba. Así, habremos de estudiar el tipo de monumento, las comparaciones tipológicas del material recuperado y el ritual funerario empleado. La valoración conjunta de estos factores permitirá ofrecer un diagnóstico sobre la realidad del monumento.

La costumbre de realizar enterramientos bajo túmulo es un hecho ciertamente habitual durante la Prehistoria. Sin tratar de ser exhaustivos habría que recordar algunos de los monumentos similares próximos y que pertenecen, a tenor de los resultados obtenidos en su excavación, a épocas dispares. La intensificación de la investigación arqueológica sobre las fases tardoneolíticas en una zona próxima a la que nos ocupa, como es el País Vasco, ha llevado consigo, al margen de otras consideraciones, el descubrimiento de multitud de manifestaciones funerarias asociadas en unos casos al fenómeno megalítico y en otros a determinadas costumbres - alternativa en muchos casos de los dólmenes- de inhumaciones bajo un túmulo de piedras sin otra estructura aparente.

Consideramos aquí estos últimos a fin de hallar concomitancias, al menos constructivas, con el ejemplar burgalés que presentamos. Así, en 1981 Vegas Aramburu publica los resultados obtenidos en el túmulo-dolmen de Kurtzebide en Letona, interpretándolo como el inicio de un dolmen por la existencia en la base de cinco cráteres excavados en el suelo virgen y que dibujan cierta forma pentagonal parangonable con una hipotética y nunca construida cámara dolménica. Pero lo que ahora nos interesa constatar en una época arcaica (2495 \pm 45 a. C.) es su forma tumular, la existencia de cráter y de una gran laja colocada sobre la estructura. Posteriores investigaciones del mismo autor en 1985 inciden igualmente sobre estructuras tumulares que forman, en la mayoría de los casos, auténticos campos de túmulos de difícil adscripción cronológica debido a la parquedad de materiales hallados. Esto ocurre en el campo tumular de Askaín y en el túmulo de Urkibi. Las características de las estructuras en estos casos no difieren mucho entre ellas, ni tampoco en relación con nuestro ejemplar. Así, se busca intencionadamente un pequeño promontorio natural para disminuir el trabajo de realce de la estructura y, sobre él, se depositan de forma un tanto arbitraria, las piedras que compondrán el túmulo.

Se advierte en ellos, tambien, una pequeña capa basal de tierra y la existencia de cráter central, mucho más acentuado en el caso de Urkibi. Por otra parte asistimos a una disminución del diámetro de los mismos que se establece entre 5 y 9 metros.

Construcciones tumulares observamos igualmente en zonas más septentrionales de la Península. 
En tierras asturianas se recoge la presencia en Tineo, de un túmulo postdolménico, el del Campiello, que tiene la particularidad de estar levantado totalmente a base de arcilla, aunque no faltan en la zona otros de piedra con un gran cráter en el centro como es el caso de El Pedregal en la misma localidad (Jordá, García y Aguado 1972-73). En el valle del Ebro, por su parte, se han descubierto también numerosas estructuras tumulares (Andrés Rupérez, 1973: 79 ss.) entre las que destaca sobre todas la Atalayuela en Agoncillo, con un diámetro de unos 12 metros y una fosa en el centro de unos 5 metros de diámetro, todo ello recubierto por un amontonamiento no muy potente de piedras y tierra (Barandiarán, 1978).

No queremos olvidar en esta sucinta relación otra serie de túmulos de distintas áreas geográficas y que se adscriben a momentos culturales dentro de la protohistoria más avanzada. Nos referimos a las necrópolis tumulares pirenaicas (Maya, Díez-Coronel y Pujol, 1973) de las primeras fases de los Campos de Urnas; a los campos de túmulos conquenses de Pajaroncillo (Almagro Gorbea, 1973) que a su estructura pétrea suman una cista de lajas en el centro; o a los enterramientos tumulares, mucho menos marcados y de cronología más moderna, de la Meseta Oriental (Cerdeño, 1981).

Hemos dejado intencionadamente para el final las manifestaciones de esta peculiar forma de enterramiento en la provincia de Burgos por cuanto que son las referencias comparativas más próximas y por ende, quizás, más válidas. A escasos trece kilómetros en línea recta se ha excavado en el término municipal de Tablada del Rudrón un túmulo campaniforme (Campillo, 1985) de estructura muy parecida al nuestro. Se trataba de un amontonamiento artificial de piedras que medía 11,90 metros de diámetro y poseía un cráter central de 2,50 metros aproximadamente. La estructura interna no difiere apenas de La Loba ya que, en esencia comparte los tres horizontes descritos: una capa inferior de arcilla compacta, un nivel más potente de bloques calizos de distintos tamaños y una capa superficial que sirve de asiento a la colonización herbácea. Además, posee, aproximadamente hacia el centro, tres fosas artificiales que sirvieron de lugar de depósito de las inhumaciones. Como vemos, estructuralmente, La Loba y el túmulo de Tablada del Rudrón comparten idénticas características: escaso porte, dimensiones, existencia de cráter y composición vertical, aunque en el túmulo de Huidobro el nivel inferior de arcilla compacta se interprete como natural, producto de la descomposición de la base calcárea.

Algo más al sur, en la necrópolis de Ubierna se reconocen una serie de tumbas de incineración circulares de pequeño tamaño y compuestas por piedras calizas dispuestas en anillos circulares muchas veces concéntricos. El centro suele estar ocupado por las ofrendas y la vasija cerámica con los restos incinerados del difunto. Analizaremos más en profundidad este tipo de estructura al tratar el ajuar funerario, pero lo que ahora nos interesa es la constatación de otro tipo de estructura tumular, próxima geográficamente a la que nos ocupa, pero con características claramente diferenciadas.

Así pues, como hemos visto, nos encontramos con que los enterramientos tumulares en la Península Ibérica no son exclusivos de una época ni una cultura concreta y evolucionan desde los más arcáicos, neoeneolíticos, hasta los más extendidos campos tumulares de la Edad del Hierro. En todo este período advertimos una cierta evolución tendente sobre todo a la disminución del tamaño y la ordenación y diferenciación lógica de los componentes. En este sentido son básicamente distintos los túmulos de Kurtzebide, Atalayuela o Tablada del Rudrón de los más modernos pertenecientes ya a la Edad del Hierro de Pajaroncillo, Sigüenza o Ubierna. Por esta razón meramente estructural pensamos que "La Loba" comparte mayor número de características y está más cerca culturalmente de los primeros que de los segundos.

Los materiales arqueológicos recuperados, aunque son escasos, también nos permiten algunas comparaciones tipológicas. En primer lugar, la gran olla de cerámica recogida en el nivel inferior del cuadro C-II, por sus características - cuello inclinado hacia afuera, panza con saliente variable sobrepasando siempre el diámetro de la boca, pared inclinada desde el máximo saliente hasta el fondo plano y con frecuentes decoraciones en el labio y cuello- podríamos incluirla dentro de la forma I de Amparo Castiella (1977) para las cerámicas de superficies sin pulir de la Edad del Hierro 
en Navarra y Rioja. Sin embargo, la misma autora cree que esta forma, compaginada con la deficiente elaboración y cuidado de la pasta y superficies, suele revestir un alto grado de localismo (Castiella, 1977: 272) y la propia forma, debido a esta caracteristica, adquiere multiples variantes. Esto se manifiesta no sólo en el perfil que, -manteniendo las constantes de cuello exvasado, diámetro de panza mayor que la boca y paredes rectas que acaban en un fondo plano-, varía al pronunciarse o restringirse el cuello, sino también en las decoraciones y el tratado de superficies. Las primeras, que ahora si de manera exclusiva afectan al labio y el cuello, se presentan como digitaciones, ungulaciones o de elementos aplicados. Nuestra pieza posee en el labio toda una sucesión de digitaciones y en el cuello un anillo de ungulaciones.

Este tipo de decoraciones ofrece escasas precisiones cronológicas ya que son motivos que se conocen desde el Neolítico, proliferan durante la Edad del Bronce y se mantienen en la Edad del Hierro. Las segundas - tratamiento de las superficies- son por lo general sin pulir, si bien se puede dar la variante de que tengan el cuello alisado y la panza rugosa. Esta última característica que comparte la olla recuperada en el túmulo de La Loba podría parecer propia de asentamientos castreños de la Edad del Hierro por su presencia en los poblados navarros y riojanos referidos por Castiella, así como en los alaveses de Solacueva de Lacozmonte (Barandiarán, 1963) o Peñas de Oro (Llanos, 1971).

Sin embargo, creemos interesante señalar cómo, desde mucho antes, podemos rastrear ejemplares en los que la zona decorada - el cuello- aparece pulida (posiblemente para resaltar la decoración o para hacerlo más agradable al tacto), y la panza intencionadamente rugosa (quizás para facilitar su sujeción y evitar el deslizamiento en el momento de ser utilizado al fuego). Así, anotamos un encadenamiento de hallazgos que van más allá de los Pirineos, registrándose en yacimientos eneolíticos de Ardeche en Grenoble (Roudil, 1965).

De contextos similares ya en nuestra península tenemos ejemplares en el complejo de Ojo Guareña (Ordax-Fusté, 1964-65) y con un sistema compositivo semejante aunque la zona sin pulir adquiere un revestimiento plástico, en la cueva de Riezu, Navarra (Beguiristain, 1979). En el yacimiento de Covarrubias dentro de la provincia de Soria y en un contexto del Bronce Antiguo -donde incluso se registra un fragmento de campaniforme Ciempozuelos- encontramos una forma cerámica similar con el mismo tratamiento de paredes (Ortego Frías, 1969). Frecuente lo es también en el yacimiento del Bronce Medio de Los Tolmos de Caracena, donde Alfredo Jimeno (1984: 78) escribe al hablar del tratamiento de superficies dentro de la cerámica:... "hay que señalar aqui que los fragmentos con bordes pertenecientes a grandes vasijas $u$ orzas, que generalmente van decorados con un cordón plástico horizontal por debajo del borde, llevan la zona correspondiente a este espacio entre cordón y borde bastante bien espatulado y a veces hasta bruñido, pero por debajo del cordón la pared de la vasija es rugosa intencionadamentem. Por último, enlazado cronológicamente con los ejemplares de la Edad del Hierro pero en un yacimiento de depósitos de hoyos en Bizkar, Alava, encontramos nuevamente un ejemplo de esta diversidad de tratamiento en la superficie de los recipientes cerámicos (Llanos, 1987: 253).

Unicamente nos resta hacer alguna comparación con el material cerámico aparecido en el vecino túmulo de Tablada del Rudrón. Aquí anotamos, entre otros materiales, un par de ollas grandes u orzas cuyas formas podemos considerar como variantes de nuestro ejemplar. En efecto, no son exactamente iguales pero poseen el cuello vuelto, la panza más saliente que la boca, las paredes inclinadas y el fondo plano, además de llevar, también, ungulaciones en el borde. Por su parte, la pasta y cuidado de las superficies es muy parecido en ambos casos por lo que pensamos que existen más afinidades que diferencias entre nuestro recipiente y los aparecidos en Tablada.

Por todo lo expuesto, nos hacemos eco de la opinión de Castiella al considerar este tipo de forma como muy habitual y propia de manufacturas locales y creemos que tanto la forma como la decoración, el tratamiento de la superficie y la composición de la pasta responden a una concepción simple y funcional del recipiente que no se puede adscribir "per se" a ningún período concreto. Así, considerando el tipo de monumento, el ritual funerario empleado y la asociación con otros materiales 
como el brazal de arquero, valoramos nuestro ejemplar como elaboración de las poblaciones autóctonas en el momento de la erección de la tumba.

Otro de los objetos recuperados en La Loba fue un brazal de arquero en arenisca de grano muy fino con dos perforaciones bicónicas en los extremos. Este tipo de piezas acompaña con mucha frecuencia el ajuar de las tumbas campaniformes. Lo vemos formando parte de dos de las tumbas más representativas del grupo Ciempozuelos, Fuente-Olmedo (Martín Valls, Delibes de Castro, 1974) y Villabuena del Fuente (Maluquer de Motes, 1960), así como en otros hallazgos interpretados también como posibles enterramientos (Grajal de Campos, León y Las Torres, Salamanca) (Delibes de Castro 1977: 120-121).

Por lo tanto, lo que parece claro es que es un objeto peculiar de ajuar fúnebre, circunstancia que no obsta para que, debido a su funcionalidad - iamortiguar el golpe de la cuerda en el momento de distensión del arco? - aparezca, con cierta frecuencia, en poblados como el de Orce (Schüle y Pellicer, 1966), el Castillo de Cardeñosa (Naranjo González, 1984) e incluso en otros más modernos como Chamartín de la Sierra (Cabré et alii, 1950). Se ha querido ver una diferenciación tipológico-geográfica entre los brazales del Sur y los de la Meseta Norte debido a la mayor longitud y estrechez de los primeros. Pero no hay que olvidar que en el Sur (Orce) también se documentan los típicos brazales de los enterramientos meseteños tipo Fuente-Olmedo o Villabuena y que en el Norte coexisten en el mismo contexto (túmulo de Tablada) ambos modelos. A lo sumo cabría pensar, como parece demostrarse en Orce (Schüle, 1981), en una matizada diferenciación cronológica que tiende a la estilización y simplificación de modelos. Por todo ello, creemos adecuado valorar nuestro ejemplar como un producto propio del primitivo ajuar funerario depositado en el túmulo de La Loba en plena Edad del Bronce, tanto por la tipología de la pieza en sí, como por su estrecha relación con los brazaletes aparecidos en el vecino túmulo de Tablada de Rudrón.

Por último, de entre los restos materiales de La Loba sólo nos resta referirnos a un objeto de bronce recogido en los niveles superiores del cuadro C-2. Se trata del botón terminal de una fíbula de pie alzado. En este caso, tanto su adscripción cultural como cronología no ofrecen ninguna duda, dado que es un modelo frecuente y muy extendido entre las necrópolis tumulares de la Segunda Edad del Hierro. Así, Schüle (1969) publica ejemplares similares en la necrópolis burgalesa de Miraveche (T. 141, $\mathrm{n}^{\circ} 24$; T. 143, $\mathrm{n}^{2} 17,19,20$ y T. 150, $\mathrm{n}^{\circ} 10$ ), las sorianas de Osma (T. 53, $\mathrm{n}^{2} 10$ ) y la Mercadera (T. 52, $\mathrm{n}^{\circ} 16$ ) que inician un jalonamiento de hallazgos que nos llevan a través de las Tierras Altas de Guadalajara (Aguilar de Anguita) (Argente Oliver, 1974: 161) y distintos poblados catalanes (La creueta, Cn'Olivé) (Navarro, 1970: 72, $n^{2} 2$ y 4) hasta el golfo de León de donde toman el tipo proveniente de Italia hacia el s. V. a. C. (Argente Oliver, 1974: 171 ss.).

Son, por tanto, en nuestro ámbito geográfico, elementos característicos del ajuar funerario de tumbas individuales de incineración bajo túmulo, costumbre que se generalizó durante la Segunda Edad del Hierro. Su presencia en el túmulo de La Loba debe entenderse, a nuestro juicio, como producto de una violación o reutilización posterior del túmulo y en el contexto de la necrópolis tumular próxima que aún está sin excavar y cuyas estructuras funerarias poseen características absolutamente distintas tales como un agrupamiento más regular de anillos de piedras de pequeño tamaño, más reducidó alzado (apenas levantan del suelo $60 \mathrm{~cm}$.) y menor dimensión $(1,5$ a $2 \mathrm{~m}$. de diámetro).

El tercero de los factores a considerar a la hora de abordar el entronque cultural de todo el conjunto es el tipo de ritual funerario empleado por las poblaciones responsables de la erección del monumento. Los restos antropológicos exhumados no ofrecen ninguna duda al respecto. Se trata, inequívocamente, de un ritual de inhumación. En toda la excavación no observamos el menor rastro de incineraciones o cremaciones, ni tan siquiera el mínimo vestigio de cenizas o cualquier evidencia de utilización del fuego con carácter ritual. Por tanto, serían poblaciones que aún detentaran el ritual de inhumación quienes construyeran el túmulo de La Loba. Dentro de esta línea, el hecho de que el estudio de los huesos nos haya permitido conocer el número de individuos enterrados (tres), la presencia de una única fosa completamente revuelta y excavada en el nivel calcáreo del páramo y la propia constatación dé la inhumación como única práctica ritual utilizada 
en el monumento, nos ofrece suficiente garantia para conjugar las tres circunstancias y considerarlas integrantes de una misma realidad.

La costumbre de la inhumación es practicada por las poblaciones prehistóricas desde tiempos inmemoriales bien en tumbas individuales, bien de forma colectiva. Pero será hacia finales del tercer milenio y de la mano de los cambios sufridos en las relaciones sociales por la introducción de la metalurgia cuando se imponga de forma casi definitiva la inhumación simple como práctica más corriente. En nuestro ámbito geográfico esta fase suele identificarse con la cultura campaniforme que unas veces aprovecha los monumentos megalíticos, en uso con anterioridad a lo largo de varias centurias para, de forma instrusiva, sepultar a sus difuntos en ellos (por ejemplo, Chabola de la Hechicera (Apellaniz y Fernández-Medrano, 1978), El Sotillo (Barandiarán et alii, 1964), Ciella (Delibes et alii, 1982), Aldeavieja de Tormes (Morán, 1931) y otras se les encuentra sepultados en fosas de inhumación individual (Fuente-Olmedo, Ciempozuelos (Riaño et alii, 1894), Villabuena del Puente,...). Que se advierta esta dualidad - aprovechamiento de dólmenes versus fosas individualeslleva a Delibes y otros $(1982,84)$ a cuestionarse si la fosa no sería el recurso al que acudirian las gentes ciempozuelos cuando faltaban los megalitos, para responderse a continuación que es difícil mantener tal planteamiento aún cuando es incuestionable que donde hay megalitos funerarios, los enterramientos campaniformes se realizan normalmente y de forma intrusiva en los mismos, relegando a un segundo término su sistema tradicional de fosa.

Si esta apreciación la trasladamos al área geográfica en la que se ubica el túmulo de La Loba, nos encontramos con ciertos matices interesantes que puntualizan tal opinión. Bien es sabido que en el norte de Burgos y más concretamente en la comarca de La Lora se desarrolla un foco megalítico de gran vigor e interés y que, hasta el presente, viene jalonado por la antigua excavación del sepulcro de corredor de Porquera del Butrón (Osaba et alii, 1971) al que se han sumado en los últimos años más de una decena de estaciones sobre las que estamos trabajando y de las que ya se han publicado dos memorias de excavación (Delibes et alii, 1982; Delibes, Rojo, y Sanz, 1986). Tanto en el dolmen de Ciella como en el de Las Arnillas se documentan materiales pertenecientes a posibles intrusiones campaniformes (cerámicas de incrustación, botones de perforación en V) lo que no hace más que potenciar la hipótesis de que estas gentes aprovechaban los dólmenes, en las zonas donde existían, para realizar sus enterramientos. Pero el hecho de que la fundación del túmulo de Tablada se realice para albergar precisamente una inhumación individual también en fosa, introduce un elemento nuevo y es una alternativa a las intrusiones campaniformes en los dólmenes. Es más, el hecho de que esta connotación de untrusión" no sea suficientemente clara en muchos monumentos ha inclinado a Delibes y Santonja (1985 y 1987) a considerar los enterramientos campaniformes como un momento más dentro de la larga perduración y utilización de que fueron objeto estas construcciones megalíticas. A esto añadiriamos nosotros ahora que no sólo ocuparon casi sistemáticamente los dólmenes, sino que alternaron sus enterramientos en estos monumentos con la construcción de túmulos de piedra que señalasen y resaltasen la fosa sobre la que depositaron al difunto. Esta costumbre que se certifica con toda veracidad en el túmulo de Tablada arraigará en las poblaciones locales y se perpetuará a lo largo de la Edad del Bronce. En efecto, tanto en el túmulo de Tablada con posterioridad al horizonte fundacional del mismo, como sobre todo en el túmulo de La Loba podemos constatar esta perduración. La inhumación simple en fosa, característica de todos los enterramientos campaniformes si exceptuamos el de La Atalayuela (excepcional en tantos aspectos) variará a lo largo de la Edad del Bronce en nuestra área geográfica donde se constatarán sucesivamente enterramientos dobles (Los Tolmos) o triples (San Román de Hornija) (Delibes, 1978).

Desde esta perspectiva, el hecho de que los restos óseos exhumados en La Loba pertenezcan a tres personas, la sensación asimismo de que es muy posible que ocupasen la fosa realizada a tal efecto, y el convencimiento de que tanto la olla de cerámica como el brazal de arquero pudieran haber sido elaborados por las poblaciones autóctonas en los primeros compases de la Edad del Bronce nos hacen pensar que esta forma de enterramiento tumular no sólo coexistió en esta zona 
con las deposiciones u ocupaciones de los monumentos megaliticos preexistentes, sino que perduró y acabó imponiéndose.

Solo futuras excavaciones podrán corroborar fehacientemente estas impresiones que por el momento se fundamentan en un reducido banco de datos, pero el hecho de que nuestras exhaustivas prospecciones en la comarca de La Lora hayan deparado el hallazgo de más de una quincena de estructuras similares, nos autorizan a ser moderadamente categóricos al respecto.

\section{BIBLIOGRAFIA}

Almagro Gorbea, M. (1973): «Los campos de túmulos de Pajaroncillo (Cuenca). Aportación al estudio de los túmulos de la Península Ibérican. Excavaciones Arqueológicas en España, 83, Madrid.

ANDRÉs RUPÉREZ, T. (1973): «El túmulo de la Atalayuela en Agoncillo (Logroño). Las estructuras tumulares del valle del Ebrow. Misceláneas de Arqueología Riojana. Logroño.

ARgente Oliver, J. L. (1974): «Las fibulas de la necrópolis celtibérica de Aguilar de Anguita (Guadalajara). Trabajos de Prehistoria, 31, Madrid.

APELlaniZ, J. M. y FernÁNDEZ-MEDRANO, D. (1978): «El sepulcro de galería segmentada de La Chabola de la Hechicera (El Villar, Alava). Excavación y restauración». Excavaciones Arqueológicas en Alava, 9. VitoriaGasteiz.

Barandiarán, I. (1963): «Excavaciones en Solacueva de Lacozmonte (Campañas 1961-62)m. Noticiario Arqueológico Hispanico, Madrid.

- (1978): «La Atalayuela: fosa de inhumación colectiva del Eneolítico en el Ebro Medio. Principe de Viana, 152 $153,39$.

Barandiarán, J. M., Fernández-Medrano, D. y Apellaniz, J. M. (1964): «Excavaciones del dolmen de El Sotillo (Rioja Alavesa). Boletín Institución Sancho el Sabio, VIII. Vitoria.

Beguiristain Gurpide, M. ${ }^{a}$ A. (1979): "Cueva del Nacedero de Riezu, Valle del Yerri». Trabajos de Arqueologia Navarra, 1. Diputación Foral de Navarra. Pamplona.

CABRÉ, J., CABRÉ DE MORÁN, E. y Molinero, A. (1950): «El castro y la necrópolis del Hierro céltico de Chamartín de la Sierra (Avila)». Acta Arqueológica Hispánica, V, Madrid.

Campillo Cueva, J. (1985): "Memoria de las excavaciones realizadas en el término de Tablada de Rudrón (Burgos). "El túmulo campaniforme de Tablada de Rudrón (Burgos)"”. Noticiario Arqueológico Hispánico, 26. Ministerio de Cultura. Madrid.

Castiella Rodríguez, A. (1977): La Edad del Hierro en Navarra y Rioja. Institución Príncipe de Viana. CSIC. Diputación Foral de Navarra. Pamplona.

Cerdeño, M. ${ }^{a}$ L. (1981): «Sigüenza. Enterramientos tumulares de la Meseta Oriental». Noticiario Arqueológico Hispánico, 11. Madrid.

Delibes de CASTRo, G. (1977): El vaso campaniforme en la Meseta Norte Española. Studia Archaeologica, 46. Universidad de Valladolid.

- (1978): «Una inhumación triple de facies Cogotas I en San Román de Hornija (Valladolid)». Trabajos de Prehistoria, 35. Madrid.

Delibes de Castro, G., Rodríguez Marcos, J. A., Sanz Minguez, C. y Val Recio, J. del (1982): «Dólmenes de Sedano I. El sepulcro de corredor de Ciellan. Noticiario Arqueológico Hispánico. 14. Ministerio de Cultura. Madrid.

Delibes de Castro, G., Rojo Guerra, M. y Sanz Minguez, C. (1986): «Dólmenes de Sedano II. El sepulcro de corredor de las Arnillas (Moradillo de Sedano, Burgos). Noticiario Arqueológico Hispánico, 27. Ministerio de Cultura. Madrid.

DeliBes de CASTRO, G. y SANTONJA, M. (1986): El fenómeno megalítico en la provincia de Salamanca. Ediciones de la Diputación de Salamanca.

- (1987): «Sobre la supuesta dualidad Megalitismo/Campaniforme en la Meseta Superior española». En W. H. Waldren y R. C. Kennard (eds.) «Bell Beakers of the Western Mediterranean. Definition, interpretation, theory and new site data. The Oxford International Conference, 1986” B. A. R. International Series, 331(1): 173-206. Oxford.

Jordá Cerdé, F., García Domínguez, E. y Aguado, J. (1972): «Notas sobre los túmulos de Campiello (Timeo) y su edad postdolménica. Zephyrus XXIII-XXIV. Salamanca.

Jimeno MARTíneZ, A. (1984): «Los Tolmos de Caracena (Soria). (Campañas 1977, 1978 y 1979). Nuevas bases para el estudio de la Edad del Bronce en la zona del Alto Duerom. Excavaciones Arqueológicas en España, 134. Ministerio de Cultura. Madrid. 
LıAnos, A. (1971): El Castro de las Peñas de Oro en el Valle de Zuva. Investigaciones Arqueológicas en Alava. Caja de Ahorros Municipal. Vitoria.

- (1978): „Bizkar. Nuevo yacimiento de depósitos de hoyos. Maetzu-Alava. Excavaciones Arqueológicas en Alava 9. Vitoria-Gasteiz.

Maluouer de Motes, J. (1960): “Nuevos hallazgos de la cultura del vaso campaniforme en la Meseta». Zephyrus, XI. Salamanca.

Martin Valls, R. y Delibes DF. CASTRO, G. (1974): «La cultura del vaso campaniforme en las campiñas meridionales del Duero: el enterramiento de Fuente-Olmedo (Valladulid). Monografias del Museo Arqueológico de Valladolid, 1. Valladolid.

Maya, J. L., Difz.Coronfl., L. y Pujol, A. (1973): «La necrópolis tumular de incineración de Pedrós, en Serós (Lérida). XIII Congreso Nacional de Arqueologia, Huelva.

Morán, C. (1931): „Excavaciones en los dólmenes de Salamanca. Memorias de la Junta Superior de Excavaciones Arqueológicas, 131. Madrid.

Navarro, R. (1970): Las fibulas en Cataluña. Instituto de Arqueologia y Paleontologia. Universidad de Barcelona. Barcelona.

Navarro González, C. (1984): «El Castillo de Cardeñosa. Un yacimiento de los inicios de la Edad del Bronce en la sierra de Avila. (Excavaciones realizadas por J. Cabré en 1932)». Noticiario Arqueológico Hispánico, 19. Madrid.

Ordax Fusté, J. (1964): „El yacimiento prehistórico de Ojo-Guareña (Burgos)». Noticiario Arqueológico Hispánico. Madrid.

Ortego Frias, T. (1969): „Covarrubias, una estación arqueológica en el término de Ciria. (Soria)». X Congreso Nacional de Arqueologia (Mahón, 1967). Zaragoza, 1969.

Osaba, B. y Abásolo, J. A.; URIBARri, J. L. y Liz, C. (1971): «El dolmen de Porquera de Butrón en la provincia de Burgosn. Noticiario Arqueológico Hispánico, XV. Madrid.

Riaño, J. F., RADA y Delgado, J. y CATAlina, J. (1894): "Hallazgos prehistóricos de Ciempozuelos». Boletín de la Real Academia de la Historia, XXV. Madrid.

RoudiL, J. (1965): "Yacimiento eneolitico de la grute de Huguetnots, Vallon Pont-D'Arc. Ardeche-Grenoble)». Gallia Prehistoire. VIII.

SchüLE, W. (1969): Die Meseta-Kulturem der iberischen Halbinsel. Berlín.

- (1981): Orce und Galera. Hamburgo.

SChüle, W. y Pellicer, M. (1966): «El cerro de la Virgen. Orce (Granada)». Excavaciones Arqueológicas en España, 46. Madrid.

Vegas Aramburu, J. I. (1981): "Túmulo-dolmen de Kurtzebide en Letona. Memoria de excavación». Excavaciones Arqueológicas en Alava, 10. Instituto Alavés de Arqueología. Vitoria-Gasteiz.

- (1985)a: «Campo tumular de Askaín. Izarza (Alava) Memoria campañas de excavaciones de 1976-78. Excavaciones Arqueológicas en Alava, 12. Instituto Alavés de Arqueología. Vitoria-Gasteiz.

- (1985)b: "Excavaciones en las Campas de Itaida (Sierra de Encia-Alava). Excavaciones Arqueológicas en Alava, 12. Instituto Alavés de Arqueologia. Vitoria-Gasteiz. 


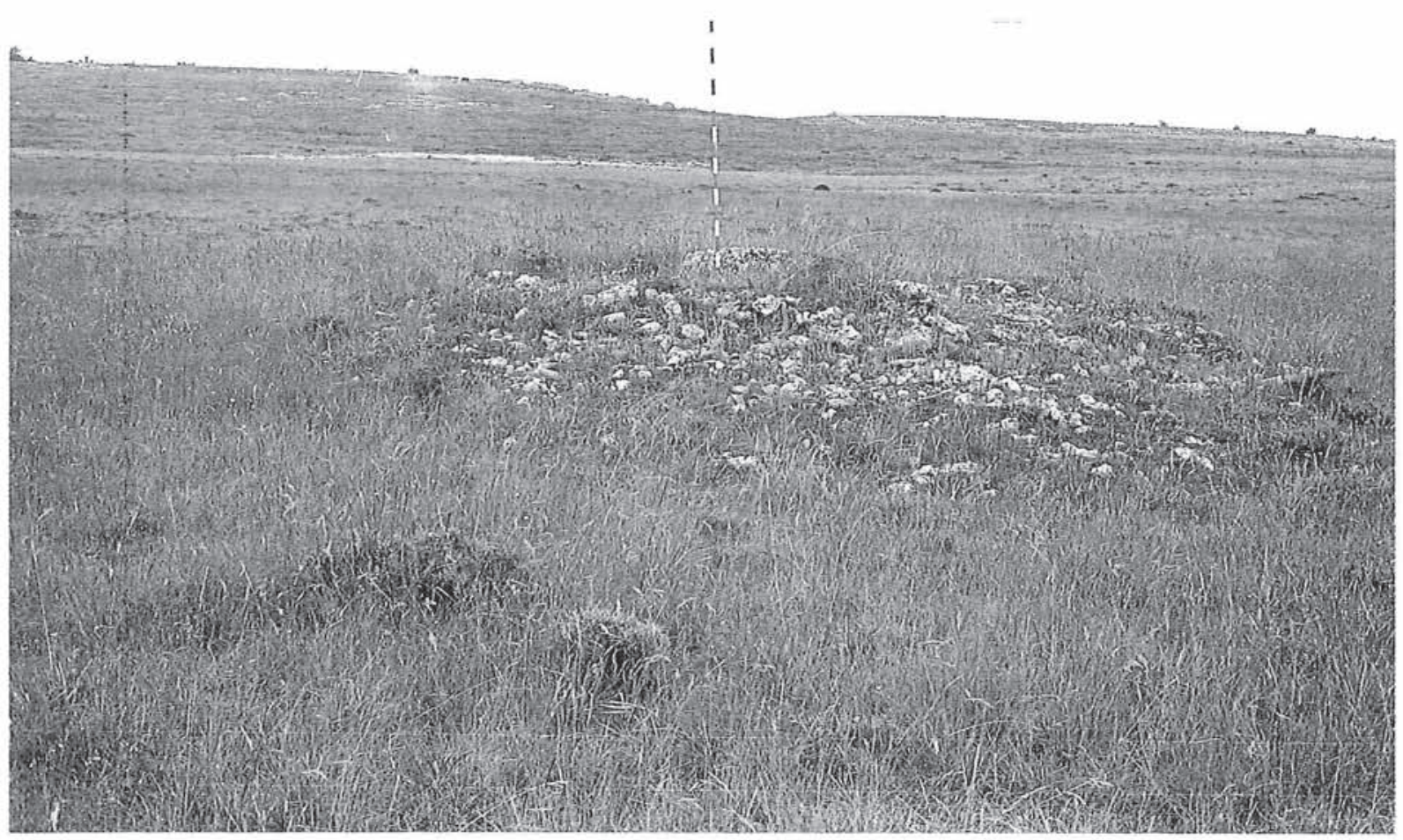

1. Vista del túmulo antes de su excavación.

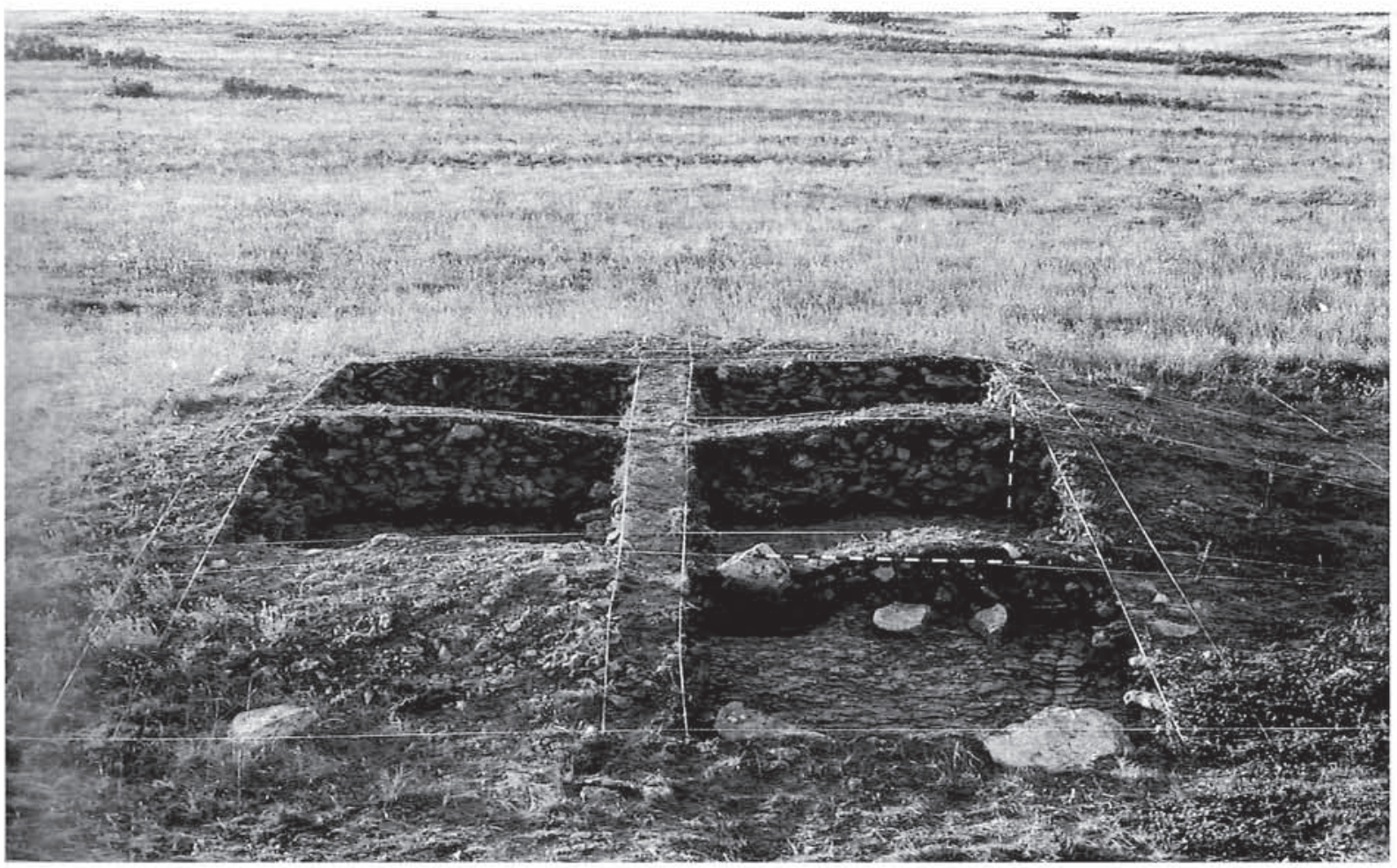

2. El túmulo de «La Loba» una vez excavado, con los testigos todavía intactos. 


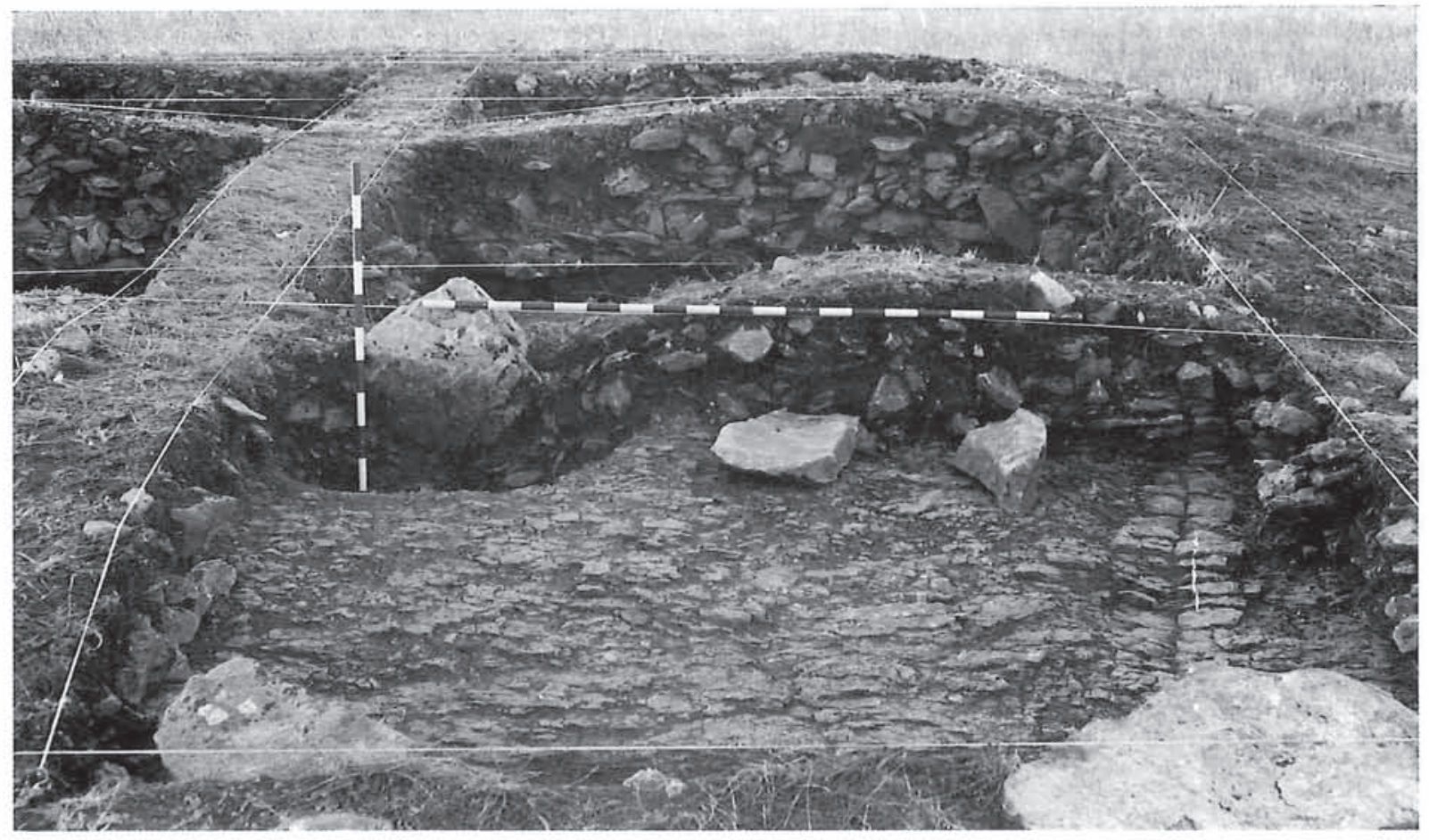

1. Detalle de una de las secciones del túmulo. Obsérvese el bloque de caliza situado sobre el foso.

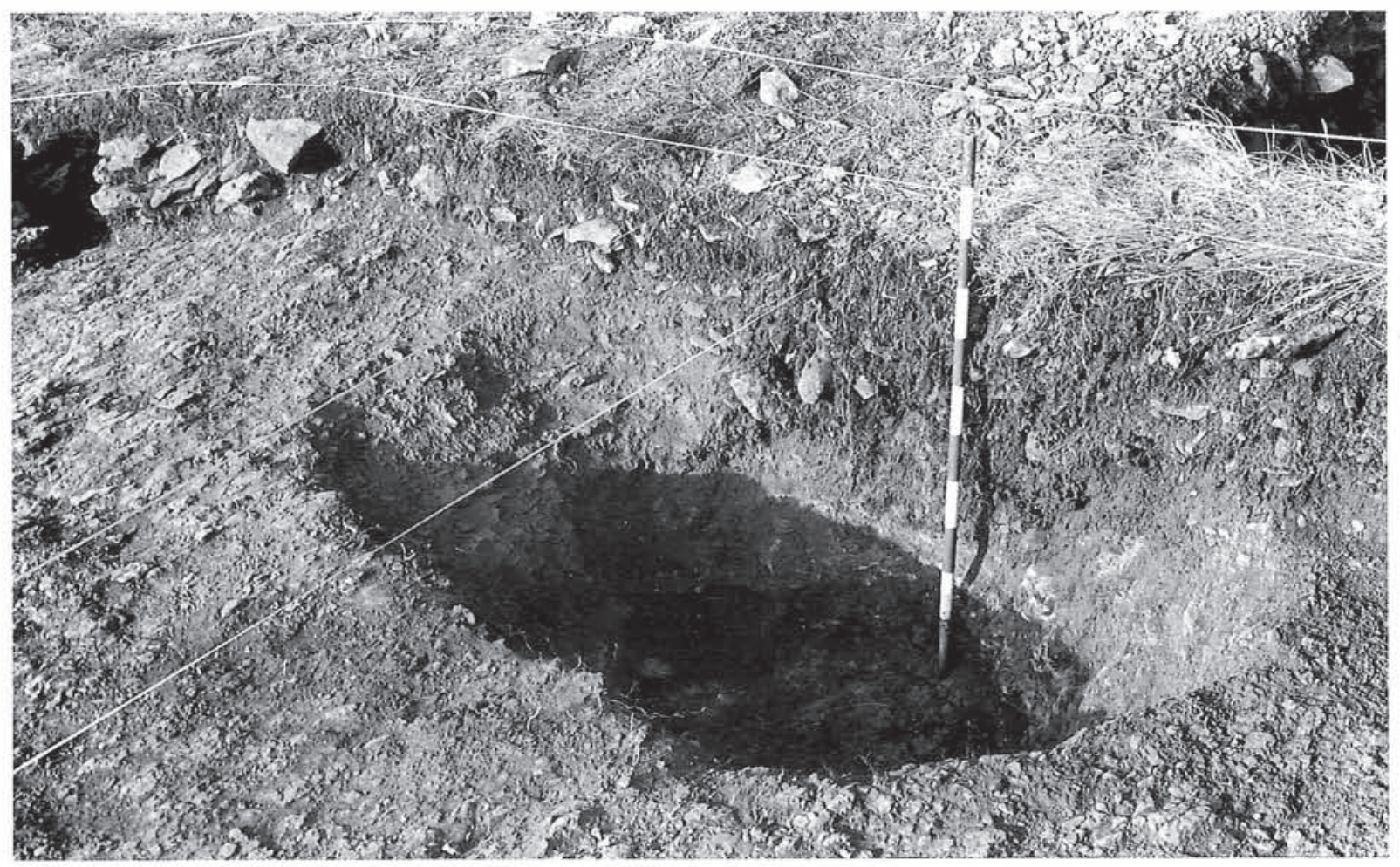

2. Detalle del foso o cráter excavado en la roca caliza del páramo. 